I Instituto de Ciencias Humanas, Sociales y Ambientales (INCIHUSA), Consejo Nacional de Investigaciones Científicas y Técnicas (CONICET), Universidad Nacional de Cuyo (UNCuyo), Mendoza, Argentina paolabayle@gmail.com

https://orcid.org/oooo-00oI-7386-552I

\title{
SENTIDOS EN PUGNA: \\ LA INSTITUCIONALIZACIÓN DE LA SOCIOLOGÍA EN LA UNIVERSIDAD DE BUENOS AIRES
}

Juan Pedro Blois. Medio siglo de sociología en

Argentina. Ciencia, profesión y política (1957-2007).

Buenos Aires: EUDEBA, 2018.

Juan Pedro Blois realiza un análisis socio-histórico del devenir de la sociología en Argentina entre I957, año en que se crea la carrera de sociología en la Universidad de Buenos Aires (UBA), y 2007, año en que, según el autor, esta pierde su centralidad al crearse otras carreras en universidades cercanas. Esta propuesta se ins cribe en investigaciones previas que han reconstruido el desarrollo de las ciencias sociales en general y de la sociología en particular. Nos referimos a los trabajos de Fernanda Beigel (2010, 20I3), Alejandro Blanco (2004, 2006), Antonio Brasil Jr. (2013), Agustina Diez (2008), Luiz Jackson y Alejandro Blanco (2014), Diego Pereyra (2007, 2010), Hélgio Trindade (2007), entre otros/as. En este marco, el libro de Blois, en línea con sus trabajos anteriores, inno- va al abordar 50 años del desarrollo de la disciplina realizando interesantes aportes tales como: las disputas en torno a los planes de estudios que guiaron y guían a la sociología como carrera universitaria; aspectos vinculados con la profesionalización y la inserción laboral de los/as sociólogos/ as (en ámbitos públicos y privados); los distintos sentidos otorgados a la carrera; el cruce entre política y profesión; la tensión entre la sociología de investigación y la libresca; el papel de las audiencias universitarias y extra universitarias en la configuración de un modelo de carrera, entre otros elementos que se despliegan en el texto en base a una rica investigación con fuentes diversas.

El libro se desarrolla en seis capítulos en los que Blois identifica rupturas 
entre distintas etapas, pero también, continuidades y herencias que aún hoy perduran. En el capítulo primero, Blois analiza el proceso de institucionalización de la sociología, extendido luego de la caída del peronismo en I955 por agentes críticos a esta experiencia. Gino Germani ocupa un lugar central en esta crónica en tanto impulsor en la UBA de un proyecto de carrera e investigación enmarcado en iniciativas ligadas a modernizar la universidad y el país; planificar para el desarrollo apelando a la ciencia y la tecnología. En ese contexto, se apostaba a que la sociología brindaría herramientas para racionalizar y democratizar las sociedades.

Para Germani y otros colegas, la sociología debía privilegiar la investigación empírica, que se pensaba como una ruptura con experiencias precedentes, asistemáticas y ensayísticas. En términos teóricos se apeló al es tructural funcionalismo y a la teoría de la modernización, y se pregonaba la neutralidad valorativa. Era sociología aplicada a los problemas del desarrollo; los/as estudiantes realizarían prácticas pre-profesionales durante su formación y el Estado se vería beneficiado con sociólogos/as expertos/as en temas de urbanización, migraciones, estratificación social.

Ya en los años I960, este modelo recibió críticas por parte del estudiantado, graduados/as e, incluso de sectores ajenos a la universidad. La apelación al estructural funcionalismo, la ruptura con el pensamiento social nacional y la casi exclusión del marxismo generaron fuertes resistencias en un contex- to de creciente politización. Sociología y política comenzaron a tener una nueva relación donde el cientificismo y la neutralidad valorativa fueron puntos de ataque. Blois aborda estos ejes en el capítulo dos, mostrando los cuestionamientos a Germani, quien finalmente se desplaza hacia el ámbito privado a mediado de los años I96o.

El campo académico argentino muestra su heterogeneidad estructural e institucional con el desarrollo de centros privados de investigación que, en ciertos momentos, actuaron como espacio de refugio. Estos centros recibieron importantes fondos internacionales generando, por un lado, capacidad para desarrollar investigaciones $y$, por el otro, fuertes críticas hacia el origen del financiamiento. En I966, un nuevo golpe de Estado atravesó a la carrera produciéndose la intervención de universidades, exclusiones y desplazamientos, que son abordados en adelante.

En el capítulo 3, Blois reconstruye la diversificación de la sociología en el período I966-I973. La investigación como eje de la formación sociológica perdió centralidad. Los/as docentes conformaban un grupo heterogéneo al frente de un estudiantado con un fuerte protagonismo y portador de un importante capital militante. En este momento se produjo la peronización de la sociología y surgió una experiencia inédita: las denominadas Cátedras $\mathrm{Na}$ cionales. Marco de esto fueron los cuestionamientos al gobierno, el rescate del pensamiento social nacional, las críticas al marxismo dogmático y los quiebres en la Iglesia católica. En 
paralelo surgieron las Cátedras Marxistas, con otras referencias teóricas y políticas, pero con una compartida valoración por el intelectual crítico y militante.

En este capítulo, por el período que abarca, se extraña la referencia al Consejo Latinoamericano de Ciencias Sociales (CLACSO). Una mirada sobre este espacio podría complejizar el análisis acerca del papel ejercido por algunos agentes académicos - incluso el del mismo Germani - y sobre la construcción de redes académicas creadas para revertir la direccionalidad Norte-Sur (Ansaldi \& Calderón, I99I; Bayle, 20I0, 20I5)

El cuarto capítulo comienza con la vuelta del peronismo al gobierno, en I973. La universidad y la sociología debían estar al servicio de la transformación social del país. Con la muerte de Perón, en I974, se desplegó en la escena nacional un giro conservador y represivo que se profundizó a partir de 1976 con el golpe cívico militar. La carrera sufrió importantes transformaciones: cierre, reapertura, cambio de edificio y aislamiento respecto de las problemáticas sociales imperantes y de la historia latinoamericana. Nuevamente los centros privados de investigación se convirtieron en un espacio de refugio. Para Blois, en estos centros se reprodujo una lógica de trabajo impulsada por fondos extranjeros: la producción de papers atentos a una agenda exógena y ensimismada. Aquí, el autor introduce la idea de sociología de enclave, un término provocador que nos invita a reflexionar sobre la producción académica en momentos de mayor heteronomía.
El capítulo cinco focaliza en la carrera a partir de la recuperación democrática. Nuevamente se suscitaron disputas en torno a la reorganización de la misma, que terminó adoptando un perfil que perduró en el tiempo. Las personas responsables de este proceso asumieron un criterio inclusivo, frente a etapas previas donde la exclusión basada principalmente en criterios políticos - había sido moneda corriente.

Los/as sociólogo/as tuvieron diversas ofertas laborales en espacios extra-universitarios. El plantel docente post dictadura también fue heterogéneo; estaba formado por profesores/as que regresaban del exilio y por graduados/as que habían permanecido en el país forjando diferentes trayectorias. Los/as estudiantes eran defensores de un modelo de sociólogo/a: aquel vinculado al ideal de intelectual público. Blois señala aquí lo que invisibilizaba el pluralismo como valor adoptado en la organización de la carrera; esto es, la configuración de una oferta académica separada de la preocupación por el mercado laboral y de la investigación. Estas omisiones quedaron registradas en el plan de estudios aprobado en I 988 que legitimó una formación sociológica sin prácticas pre-profesionales y con un perfil básicamente académico.

En el último capítulo, el autor reconstruye el campo de la sociología argentina desde los años I990 al 2007 , arrojando interesantes pistas a profundizar. Este período involucra importantes cambios en el país; desde la implementación de un modelo neoliberal en la economía y sus consecuen- 
cias en el sistema universitario, hasta su crisis a principios del presente siglo. En el sistema universitario se incrementaron los espacios de formación sociológica de grado y posgrado, al tiempo que la investigación en espacios privados se vio afectada por el retraimiento de fondos internacionales.

Blois da cuenta de varios procesos que atravesaron la práctica sociológica: la creación del Programa Nacional de Incentivos; el otorgamiento de subsidios públicos a proyectos colectivos; la multi ocupación y la precarización laboral de los/as sociólogos/as; la inserción laboral en espacios extra-académicos (consultoría y recursos humanos en empresas privadas); la implementación de criterios de evaluación elaborados en los centros académicos mundiales que privilegian el paper sobre otros formatos. Respecto de este punto creemos que, si bien estos criterios se han extendido en distintas instituciones académicas, no han permeado de la misma forma y con el mismo peso en todos los espacios de producción del conocimiento y en todas las disciplinas. La heteronomía, tanto en la producción como en la circulación y evaluación del conocimiento científico, es un rasgo que atraviesa con distinto peso los campos académicos periféricos y centrales (ver Beigel, Gallardo \& Bekerman, 20I8).

La primera década de este siglo encontró a la carrera en la UBA con un perfil principalmente académico. Perdura aún el debate en torno a los interrogantes ¿qué es y para qué sirve la sociología? Las respuestas, dice el autor, están condicionadas por los capi- tales y credenciales de quienes contestan. Creemos, además, que las mismas suelen teñirse de un imperativo moral del que carecen otras carreras.

A modo de cierre, es justo señalar que el autor - aunque da cuenta de la literatura que abordan otros espacios al focalizar en la UBA posiblemente invisibiliza otros derroteros locales que, si bien no tuvieron el peso de esta carrera (por los recursos materiales y humanos que movilizó y por los debates que allí se suscitaron, entre otros motivos), su análisis podría enriquecer una reconstrucción con pretensión nacional.

Dicho esto, creemos que el libro que nos ofrece Juan Pedro Blois además de reconstruir minuciosamente distintas aristas del desarrollo de una disciplina tiene un potencial extra: su invitación a pensar las prácticas sociológicas hoy, la formación universitaria y su relación con la política y el ejercicio profesional. Continuar el análisis a partir de 2007, cuando Argentina experimentaba un aumento en el presupuesto nacional en ciencia y tecnología y su retraimiento a partir de los cambios políticos ocurridos en 2015, puede arrojar nuevas pistas sobre los espacios de inserción de los/as sociólogos/as. Creemos que el análisis de otros espacios institucionales que conversen con el trabajo de Blois serán vitales en esta tarea de reconstrucción del derrotero de la sociología en Argentina.

Recibido en I8/6/2019 | Aprovado en 9/7/20I 9 


\section{REFERENCIAS BIBLIOGRÁFICAS}

Ansaldi, Waldo \& Calderón, Fernando. (I99I). La búsqueda de América Latina. Cuadernos, I.

Bayle, Paola. (2015). Conectando Sures: la construcción de redes académicas entre América Latina y África. Íconos. Revista de Ciencias Sociales, I/53, p.I53-I70.

Bayle, Paola (20Io). La migración forzosa de una población calificada: El Programa de Reubicación de Cientistas Sociales, CLACSO y el exilio chileno (I973-I976). In: Beigel, Fernanda (Dir.). Autonomía y dependencia académica. Universidad e investigación científica en un circuito periférico: Chile y Argentina (I950-1980). Buenos Aires: Biblos. p. 233-269.

Beigel, Fernanda (Ed.). (2013). The politics of academic autonomy in Latin America. London: Ashgate.

Beigel, Fernanda (Dir.). (2010). Autonomía y dependencia académica. Universidad e investigación científica en un circuito periférico: Chile y Argentina (1950-1980). Buenos Aires: Biblos.

Paola Adriana Bayle es doctora en ciencias sociales (UNCuyo, Argentina), investigadora adjunta (CONICET). Intereses: Sociología latinoamericana, migraciones y movilidad académica, internacionalización científica y universitaria, dependencia académica. Publicaciones: "Conectando Sures. La construcción de redes académicas entre América Latina y África”, "Chile y Reino Unido: vaivenes de una relación diplomática no siempre tan cordial (I970-I980)” y, con Juan Jesús Morales, "Itinerario del Diccionario de Ciencias Sociales en español (UNESCO, I952-I976)" 
Beigel, Fernanda; Gallardo, Osvaldo \& Bekerman, Fabiana. (2018). Institutional Expansion and Scientific Development in the Periphery: The Structural Heterogeneity of Argentina's Academic Field. Minerva, 56, p.305-33I. Disponível em: <https://doi.org/ıo.ı 07/SI IO24-OI7-9340-2>.

Blanco, Alejandro. (2006). Razón y modernidad. Gino Germani y la sociología en la Argentina. Buenos Aires: Siglo XXI.

Blanco, Alejandro. (2004). La sociología: una profesión en disputa. In: Neiburg, F. \& Plotkin M. (Comp.). Intelectuales y expertos. Buenos Aires: Paidós.

Brasil Jr., Antonio. (2013). Passagens para a teoria sociológica: Florestan Fernandes e Gino Germani. São Paulo: Hucitec.

Diez, María Agustina. (2008). Dos caras frente al espejo: una comparación de las sociologías argentina y chilena entre I966 y 1976. Sociohistórica. Cuaㅇํ dernos del CISH, 23-24, p. 39-79.
Jackson, Luiz \& Blanco, Alejandro. (20I4). Sociología no espelho. Ensaístas, cientistas sociais e críticos literários no Brasil e na Argentina (I939-I970). São Paulo: Editora 34.

Pereyra, Diego (compilado). (20IO). El desarrollo de las ciencias sociales. Tradiciones, actores e instituciones en Argentina, Chile, México y América Central. San José de Costa Rica: FLACSO. (Serie Cuadernos de Ciencias Sociales). Pereyra, Diego. (2007). Cincuenta años de la carrera de sociología de UBA. Algunas notas contracelebratorias para repensar la historia de la sociología en Argentina. Revista Argentina de Sociología, 9, p. I53-I59.

Trindade, Hélgio (Coord.). (2007). Las ciencias sociales en América Latina en perspectiva comparada. México: Siglo XXI. 